\title{
The effect of emotional regulation training on the sexual function and sexual satisfaction of women with multiple sclerosis (MS) referring to Iranian MS Research Center
}

\author{
Fateme Najafi ${ }^{1}$, Mohammad Sahebalzamani ${ }^{2}$, Hojjatollah Farahani ${ }^{3}$ \\ ${ }^{1}$ MSc of Psychiatric Nursing, Tehran Medical Sciences, Islamic Azad University, Tehran, Iran \\ ${ }^{2}$ Associate Professor, PhD of Educational Management, Tehran Medical Sciences Islamic Azad University, Tehran, \\ Iran \\ ${ }^{3}$ Assistant professor, PhD of Psychometrics, Tehran Medical Sciences, Islamic Azad University, Tehran, Iran
}

\begin{abstract}
Background: Multiple sclerosis (MS) affects people's physical and mental aspects, including the quality of sexual relationships. In this study, the effect of emotional regulation training on the sexual function and sexual satisfaction of MS patients was investigated.

Materials and methods: This quasi-experimental study was performed on 98 women with MS who were referred to the Iranian MS Research Center in 2016. The emotional regulation training program consisted of eight two-hour sessions. The demographic information, emotional regulation skills questionnaire (ERSQ), female sexual function inventory (FSFI) and sexual satisfaction scale for women (SSSW) questionnaires were completed before and after the intervention.

Results: The emotion regulation status of 93.9 percent of the subjects was at a moderate and high level before the intervention, which increased by 100 percent after the intervention. In the case of sexual function and sexual satisfaction, the pre-test rate was 83.7 and 98.9 percent, respectively, which reached to 97 and 100 percent after intervention. The mean of emotional regulation, sexual function, and sexual satisfaction before intervention was 59.97, 20.24, and 92.00, which after intervention reached to 77.08, 26.98 and 95.38, respectively. Paired t-test showed a significant increase in the mean of the research variables after intervention $(\mathrm{p}<0.05)$.

Conclusion: Considering the efficacy of emotional regulation training intervention, it is recommended to design and implement such interventions for patients with MS. To this end, it will provide a circumstance for improving their sexual function and satisfaction and also their quality of life.
\end{abstract}

Keywords: Emotional regulation, Sexual function, Sexual satisfaction, Women, Multiple sclerosis.

Cited as: Najafi F, Sahebalzamani M, Farahani H. The effect of emotional regulation training on the sexual function and sexual satisfaction of women with multiple sclerosis (MS) referring to Iranian MS Research Center. Medical Science Journal of Islamic Azad University, Tehran Medical Branch 2020; 30(1): 92-100.

Correspondence to: Mohammad Sahebalzamani

Tel: $+982147916901-2$

E-mail: m_szamani@iautmu.ac.ir

ORCID ID: 0000-0003-1730-6770

Received: 15 Jan 2019; Accepted: 29 Jun 2019 
مجله علوم يزشكى دانشگاه آزاد اسلامى

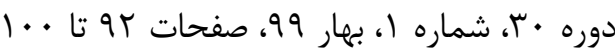

Original

Article

\section{تاثير آموزش تنظيم هيجانى بر عملكرد و رضايت جنسى زنان مبتلا به مولتيبل اسكلروزيس (ام اس) مراجعه كننده به مركز تحقيقات ام اس ايران}

\section{فاطمه نجفى'، محمد صاحب الزمانى؟ حجت الله فراهانى}

'كارشناس ارشد روانيرستارى، علوم يزشكى تهران دانشكاه آزاد اسلامى، تهران، ايران

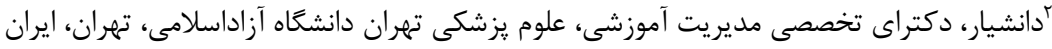

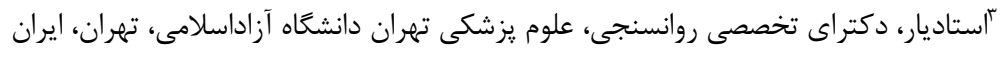
جككيه

سابقه و هدف: بيمارى مولتيبل /سكلروزيس (ام /س) جنبههاى جسمى و روانى افراد، از جمله كيفيت روابط جنسى را متاثر مى كند.

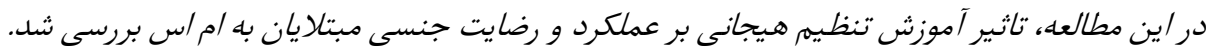

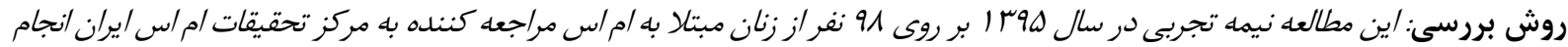

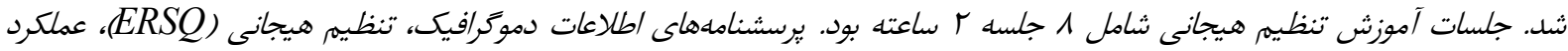

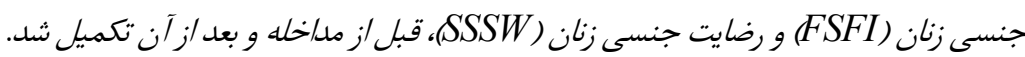

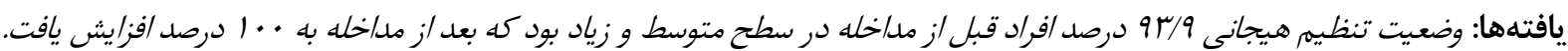

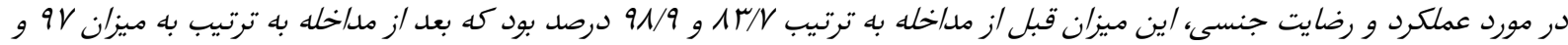

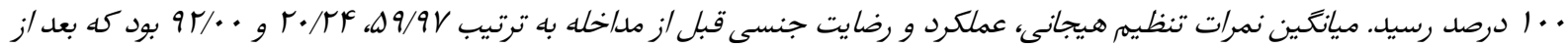

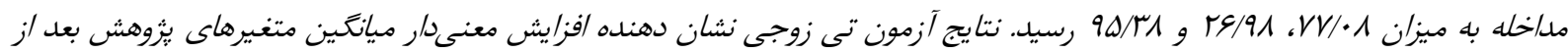

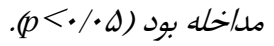
نتيجه كيرى: با توجه به اثربخشى مداخله تنظيمر هيجانى، طراحى و اجراى /ين مداخله به صورت هدفمند براى مبتالايان به /م /س توصيه

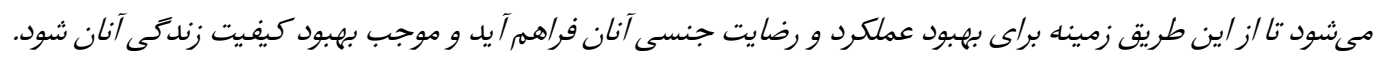

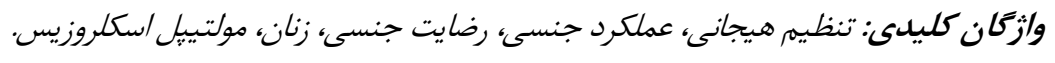

نشان داد كه II IV ميليون نفر مبتلا به حداقل يك بيمـارى مـزمن

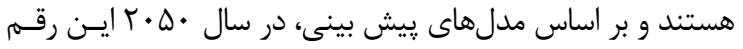

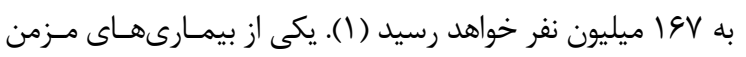

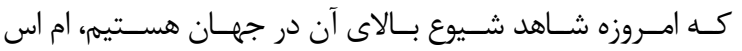

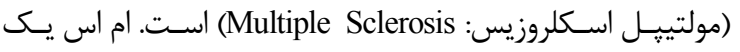

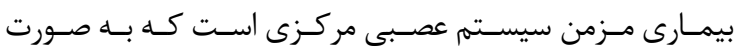

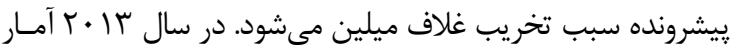

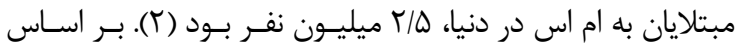

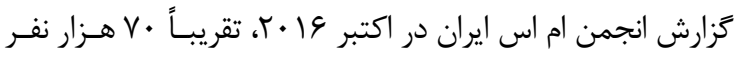

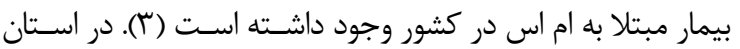

مقدمه

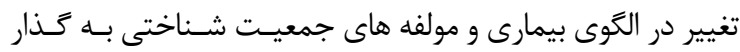

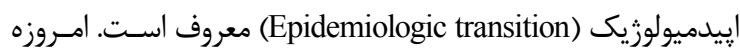
سومين كذار إيدميولوزيك در جريان است و شيوع بيمـارىهـاى إسي

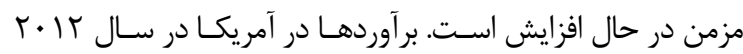

آدرس نويسنده مسئول: تهران، دانشكاه آزاد اسلامى، دكتر محمد صاحب الزمانى (email: m_szamani@iautmu.ac.ir) ORCID ID: 0000-0003-1730-6770 تاريخ دريافت مقاله: 


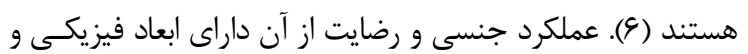

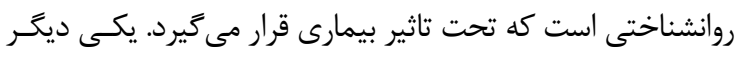

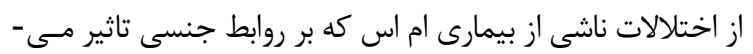

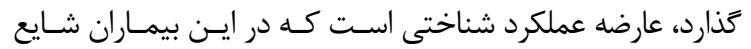

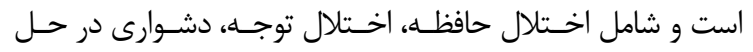
مسائل و كندى تحليل اطلاعات است (ك، • ().

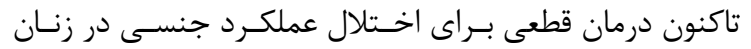

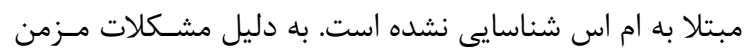

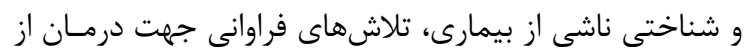

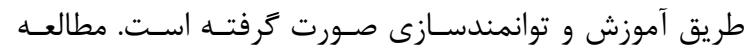

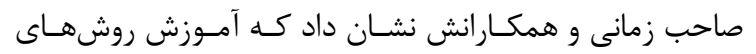

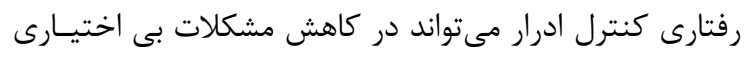

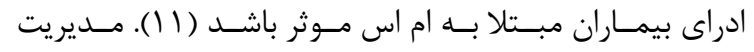

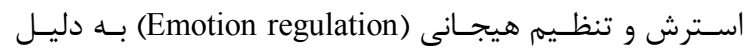

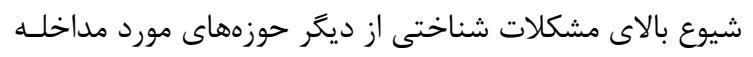

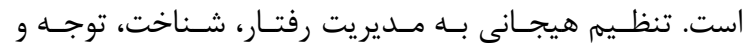

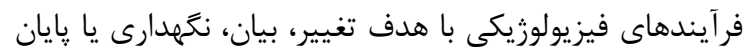

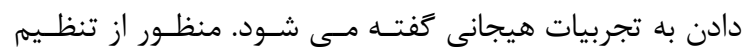

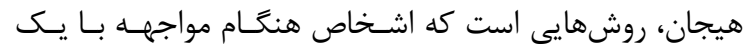

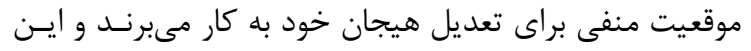

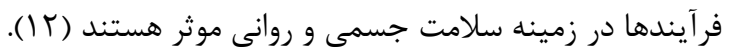

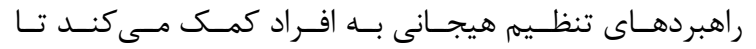

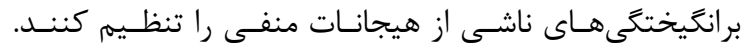

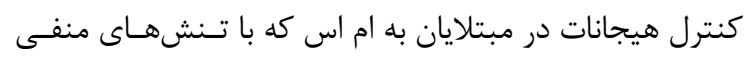

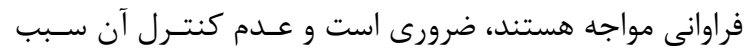

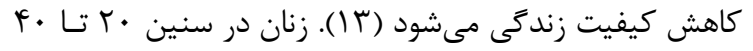

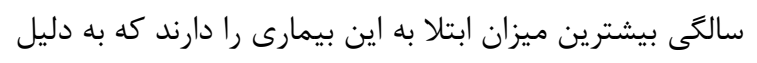

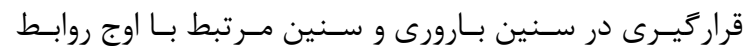
جنسى، امكان هيجانات منفى در آنان بيشتر است. اين شـرايط فيط

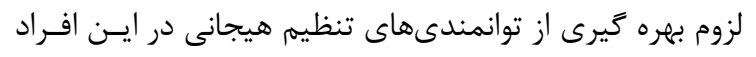

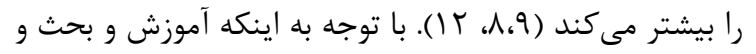

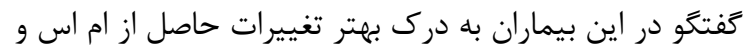

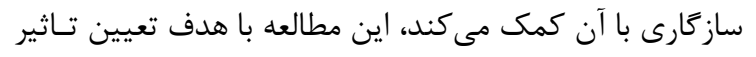

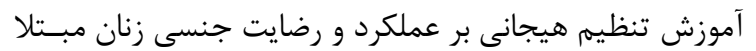

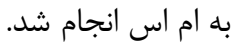

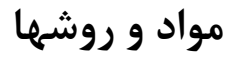

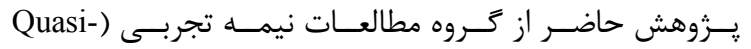

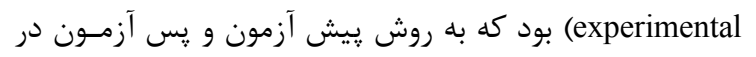

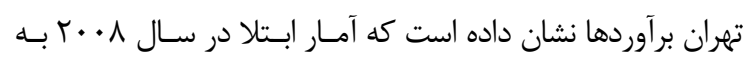

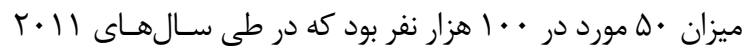

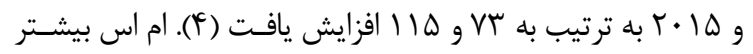

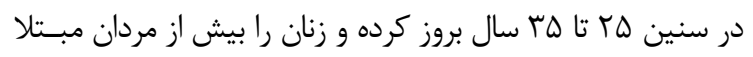

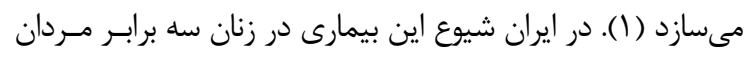

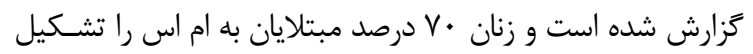

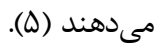

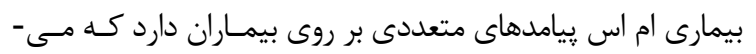

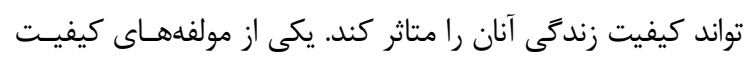

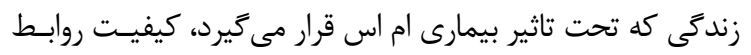

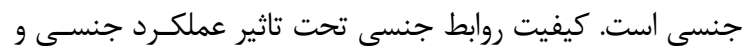

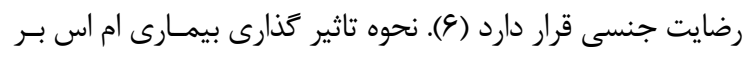

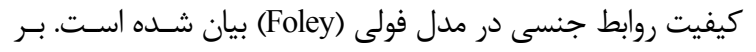

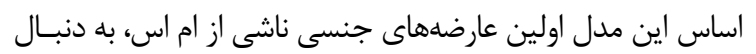

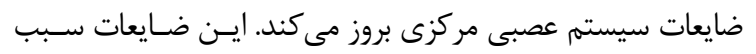

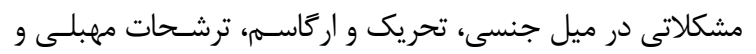

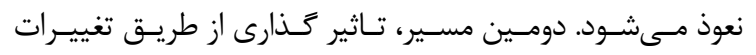

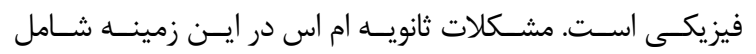

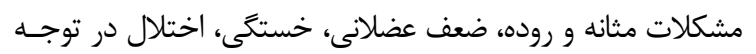

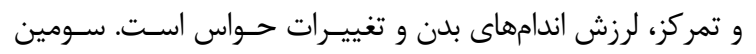

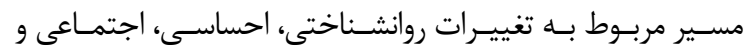

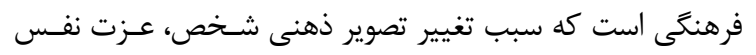

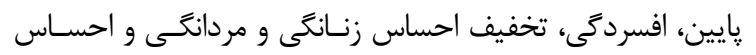
كم شدن جذابيت مىشود (V).

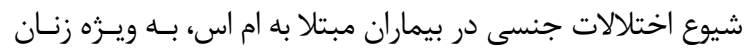

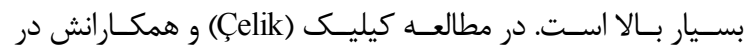

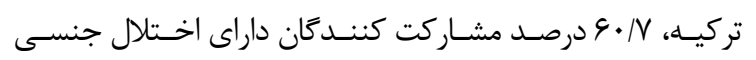

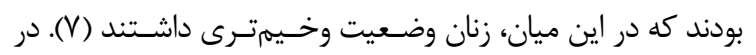

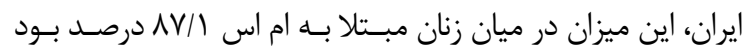

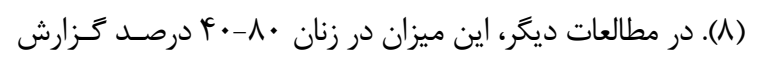

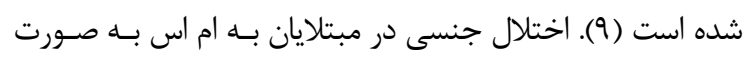

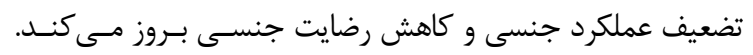

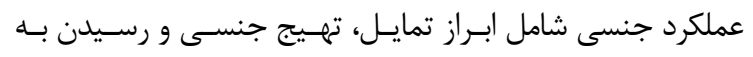

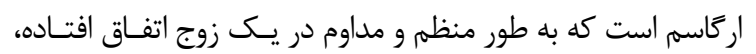

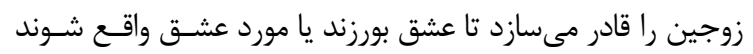

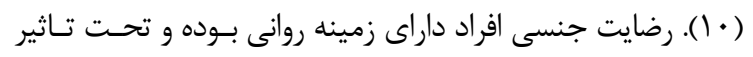

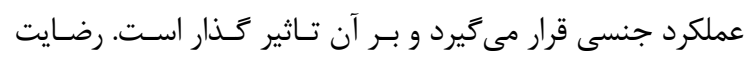

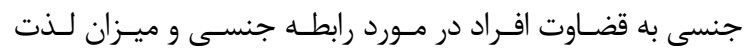

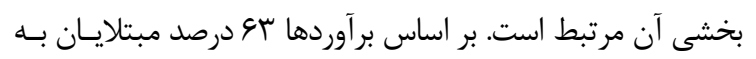

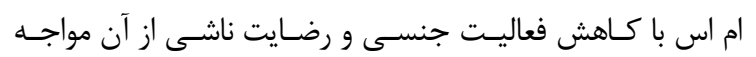


Sexual Satisfaction ( ) و مقياس رضايت جنسى زنان (FSFI) (Scale for Women (SSSW) دموَرافيك شامل 9 سوال جمعيت شناختى و r سوال مربوط

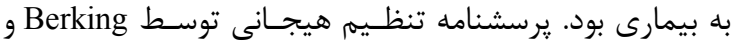
نام Znoj

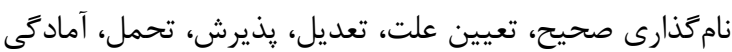

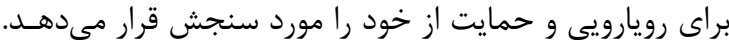

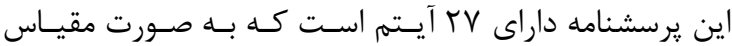

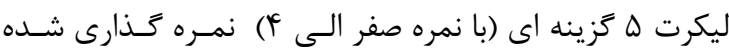

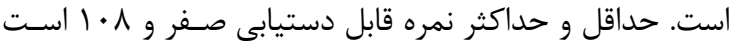

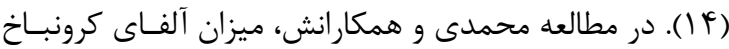
براى مجموع ابعاد بهو/• برآورد شده و پايايى آن تاييد شد.

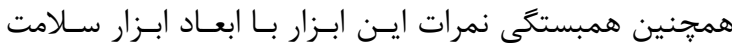

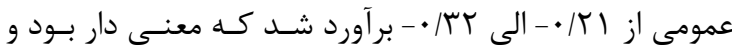

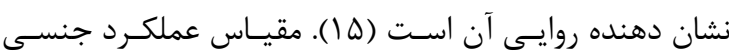

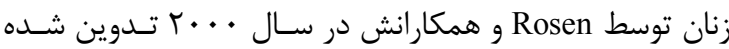

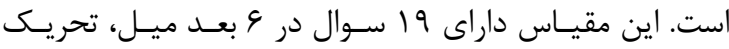

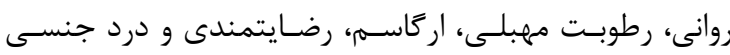

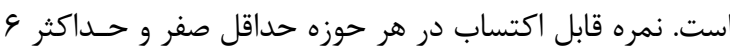
بود و در كل مقياس به ترتيب صفر و وب است. نمره 19 نقطــهـ

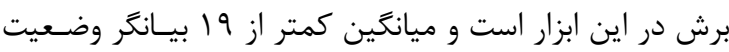

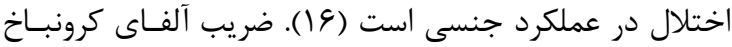

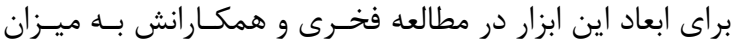

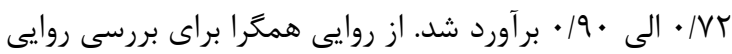

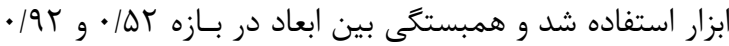

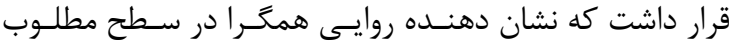

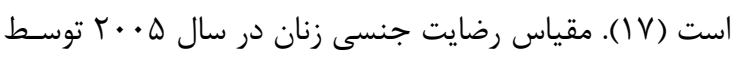
Meston

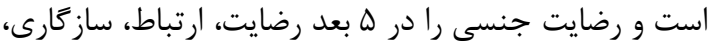

سال هوبا انجام شد. جامعه اين يزوهش را كليه زنـان مبـتلا

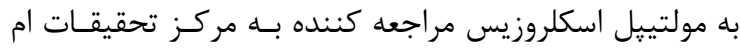
اس ايران، واقع در بيمارستان سـيناى تهـران، تشـكيل دادنـد.

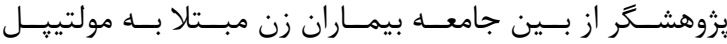
اسكلروزيس مراجعه كننده به مركز تحقيقات ام اس ايـران 91 بران

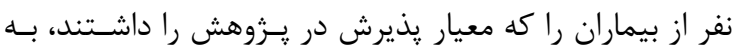

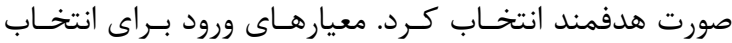

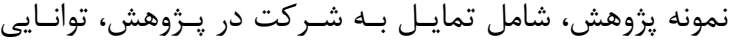

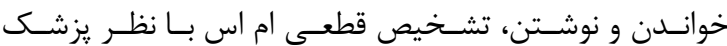
متخصص مغز و اعصاب، حداقل سابقه r سال ابتلا به بيمـارى،

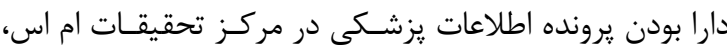

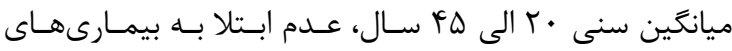
روانى، عدم وجود مشكلات مربوط به توانـايى يـادكيرى، عـدمام

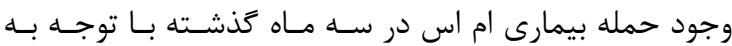
مستندات يزشكى، باردار نبودن، عدم ابتلاى همزمان بـه سـاير بيمارىهاى مزمن، امكان دسترسى به بيمار و وِيكيرى وضعيت

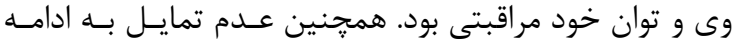

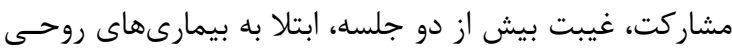

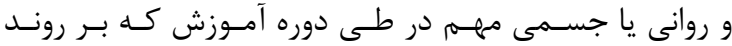
يادگيرى موثر باشد و مهاجرت و فوت به عنــــان معيـار خـروج

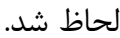
جلسات آموزش تنظيم هيجانى شامل 1 جلسه r سـاعته بـود.

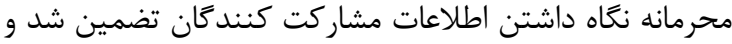

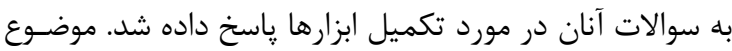
و هدف جلسات هشت كانه به صورت جدول 1 بود.

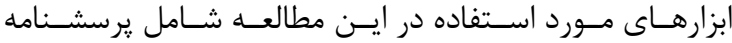

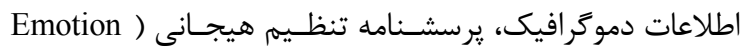
(Regulation Skills Questionnaire (ERSQ) عملكرد جنسى زنسان ( Female Sexual Function Index

\begin{tabular}{|c|c|c|}
\hline هدف & 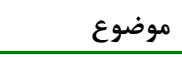 & جلسه \\
\hline معرفى تحقيق، روش كار و اهداف آن، كسب رضايت آكاهانه، هماهنكَى زمان و مكان جلسات آتى، ارائه & معارفه و مقدمه & اول \\
\hline \multicolumn{3}{|l|}{ 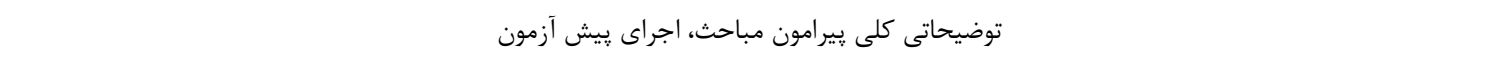 } \\
\hline آموزش در زمينه آكاهى از هيجانات مثبت (شادى، عشق و ...) و لزوم توجه به آن & 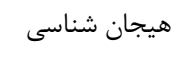 & دوم \\
\hline ارزيابى ميزان آسيب خذيرى هيجانى و مهارتهاى مرتبط اعضاء & 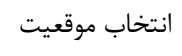 & سوم \\
\hline ايجاد تغيير در موقعيت برانكيزاننده هيجان و كنترل برانكَيزاندهها & اصلاح موقعيت & جهارم \\
\hline توانايى تغيير توجه از هيجان منفى به مثبت و كَسترش حوزه توجه & 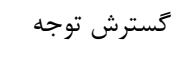 & ينجم \\
\hline آموزش ارزيابى مجدد، تجربه ذهنى و ابراز هيجان مثبت و مرور & 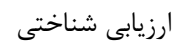 & ششم \\
\hline تغيير در ييامدهاى رفتارى و فيزيولوزيك هيجان از طريق ارزيابى مجدد هيجان منفى & تعديل ياسخ & هفتم \\
\hline ارزيابى و جمع بندى آموزش، برنامه ريزى براى كاربرد آن و اجراى يس آزمون & 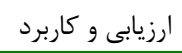 & 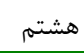 \\
\hline
\end{tabular}


كمتر از له درصد استفاده شد.

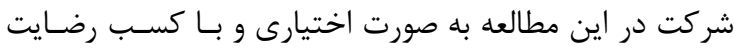

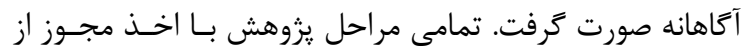

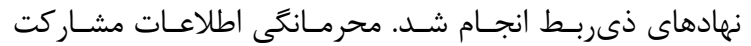

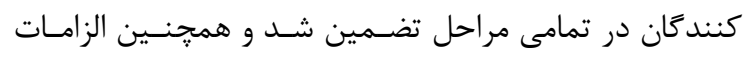

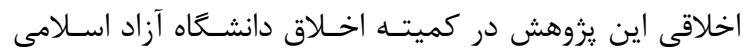

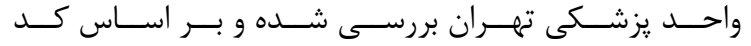
IR.IAU.TMU.REC.1395.12 مورد تاييد قرار كرفت.

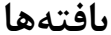

يافتهاى مربوط به متغيرهـاى جمعيـت شـناختى و متغيرهـاى

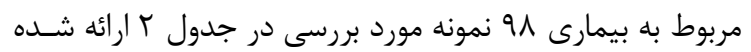

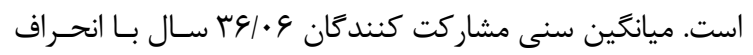

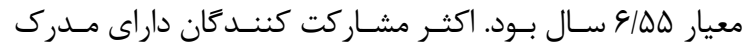

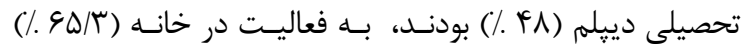

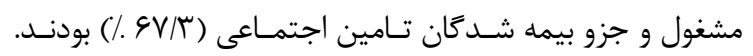

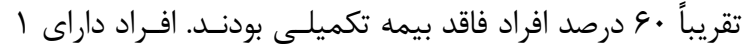

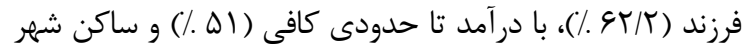

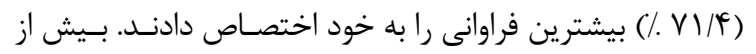

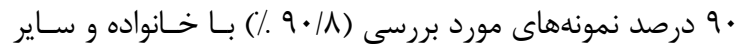

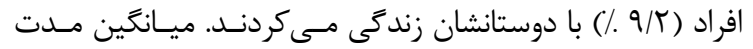

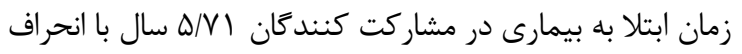

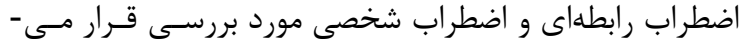

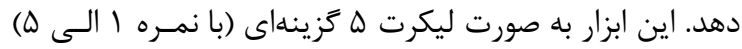

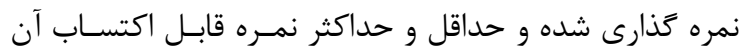

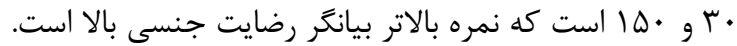

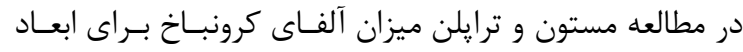

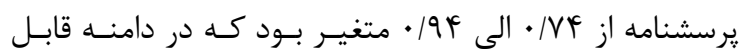

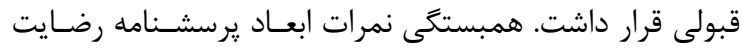

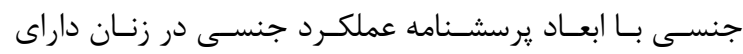

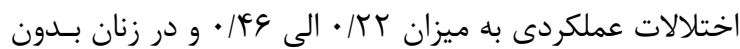

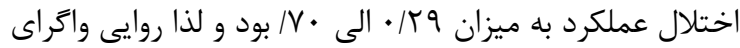
آن تاييد شد (1) (1).

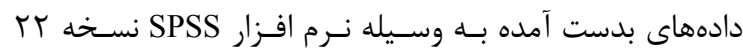

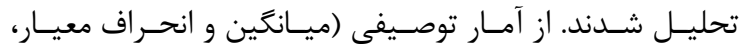
فراوانى و درصد) جهت كزارش يافتههاى توصيفى استفاده شد.

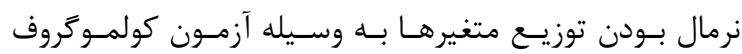

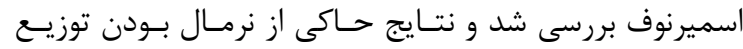

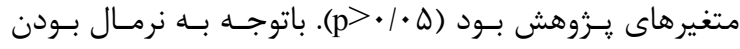

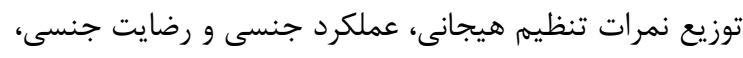

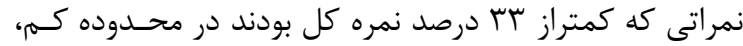

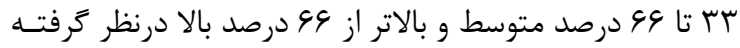

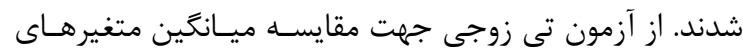

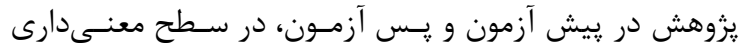

جدول r. توزيع متغيرهاى دموكرافيك زنان مبتلا به ام اس مراجعه كننده به مركز تحقيقات ام اس

\begin{tabular}{|c|c|c|c|c|c|}
\hline تعداد (درصد) & سطوح متغير & متغير & تعداد (درصد) & سطوح متغير & متغير \\
\hline S1 (GT/Y) & ا فرزند & تعداد فرزند & Ir & زير •r & سن (سال) \\
\hline$r F(\Gamma Y / V)$ & ك فرزند & & $\Delta \Lambda(\Delta q / \Gamma)$ & $r \cdot-r \cdot$ & \\
\hline$r(r / 1)$ & بيش از ب فرزند & & $r V(T V / \Delta)$ & بالاى f r & \\
\hline$T V(T V / Y)$ & كافى & در آمد & $1 \Lambda(\mid N / F)$ & زير دييلم & تحصيلات \\
\hline$\Delta \cdot(\Delta \mid)$ & تا حدى كافى & & $F \vee(F \wedge)$ & دييله & \\
\hline$r \mid(r \mid / F)$ & ناكافى & & $1 \cdot(1 \cdot / \pi)$ & فوق دييلم & \\
\hline$V \cdot(V / / F)$ & شهر & محل سكونت & $r r(T r / F)$ & ليسانس و بالاتر & \\
\hline$r \Lambda(T V / \varphi)$ & روستا & & $g \varphi(\varphi \Delta / r)$ & خانه دار & شغل \\
\hline$r V(\Gamma V / \Lambda)$ & $r-\omega$ & مدت ابتلا (سال) & $11(11 / \Gamma)$ & بيكار & \\
\hline$\Delta I(\Delta T)$ & $\Delta-1$. & & $r r(T / Q / \Delta)$ & شاغل & \\
\hline $1 \cdot(1 \cdot / r)$ & بالاى · & & $99(9 V / \%)$ & تامين اجتماعى & بيمه \\
\hline$r T(Y r / F)$ & ا بار & دفعات بسترى & $19(19 / 4)$ & خدمات درمانى & \\
\hline$r \cdot(r \cdot 19)$ & ك بار & & $9(9 / r)$ & كميته امداد & \\
\hline $\mathbb{I r}(\mid r / r)$ & r بار & & $F(F / 1)$ & ساير & \\
\hline$T^{F}(Y F / Q)$ & F بار & & $\psi \cdot(\psi \cdot / \Lambda)$ & دارد & بيمه تكميلى \\
\hline $9(9 / \pi)$ & ه بار و بيشتر & & $\Delta \Lambda(\Delta Q / \Gamma)$ & ندارد & \\
\hline
\end{tabular}


جدول rا. وضعيت تنظيم هيجانى، رضايت و عملكرد جنسى در زنان مبتلا به ام اس مراجعه كننده به مركز تحقيقات ام اس

\begin{tabular}{|c|c|c|c|}
\hline بعد از آموزش & قبل از آموزش & سطوح متغير & متغير \\
\hline (درصد) تعداد & (درصد) تعداد & & \\
\hline$\cdot(\cdot)$ & $9(9 / 1)$ & كم & ننظيم هيجانى \\
\hline$V Y(V Y / Q)$ & $\vee \wedge(\vee ৭ / \varphi)$ & متوسط & \\
\hline$\Gamma \varphi(\Gamma \varphi / \Delta)$ & $\mid f(\mid F / T)$ & زياد & \\
\hline$r(r / 1)$ & $19(19 / \pi)$ & كم & عملكرد جنسى \\
\hline$G T(G T / T)$ & $G T(G T / T)$ & متوسط & \\
\hline rr $(r / V)$ & $r \cdot(r \cdot / F)$ & زياد & \\
\hline$\cdot(\cdot)$ & $1(1 / 1)$ & Sم & رضايت جنسى \\
\hline $9 \Lambda(99 / 4)$ & $V \Delta(V \varepsilon / \Delta)$ & متوسط & \\
\hline$r \cdot(r \cdot \mid 9)$ & $T Y(Y Y / F)$ & زياد & \\
\hline
\end{tabular}

جدول F. شاخصهاى توصيفى متغيرهاى تنظيم هيجانى، رضايت و عملكرد جنسى و ابعاد آن ها قبل و بعد از انجام مداخله در

\begin{tabular}{|c|c|c|c|c|c|}
\hline \multicolumn{6}{|c|}{ زنان مبتلا به ام اس به همراه نتايج آزمون t زوجى } \\
\hline \multicolumn{2}{|c|}{ نتايج آزمون تى زوجى } & \multirow{2}{*}{ انحر اف معيار 土 ميانكين آموزش } & \multirow{2}{*}{ انحراف معيار 土 ميانكين آموزش } & \multirow[t]{2}{*}{ ابعاد متغير } & \multirow[t]{2}{*}{ متغير } \\
\hline مقدار p p & مقدار t & & & & \\
\hline$<\cdot|\cdot \cdot|$ & $V / \Delta q$ & $q / \Delta q \pm r / r \Delta$ & $9 / \Lambda \Lambda \pm r / r$ & آكاهى & تنظيم هيجانى \\
\hline$<\cdot \mid \cdot \cdot 1$ & N/9V & $9 / 9 \vee \pm r / V \varphi$ & $\Delta / \Lambda F \pm r / \varnothing \Delta$ & تشخيص & \\
\hline$<\cdot \mid \cdot \cdot 1$ & $\Delta / \Delta q$ & $1 / 99 \pm r / 99$ & $9 / V \Delta \pm 1 / 9 \varphi$ & نامكذارى صحيح & \\
\hline$<\cdot|\cdot \cdot|$ & $r / \Delta \varphi$ & $V / q r \pm r / l r$ & $g / F \Lambda \pm r / r r$ & تعيين علت & \\
\hline$<\cdot|\cdot \cdot|$ & $V / 9 \Lambda$ & $1 \cdot 1 \cdot r \pm r / 4 q$ & $V / r F \pm 1 / 9 r$ & تعديل & \\
\hline$<\cdot|\cdot \cdot|$ & V/ra & $q / r r \pm r / r q$ & $9 / 91 \pm 1 / 4 V$ & ل يذيرش & \\
\hline$<\cdot \mid \cdot \cdot 1$ & $r / \Psi_{\Delta}$ & $V|\Lambda| \pm r|q|$ & $G / V V \pm r / Y r$ & تحمل & \\
\hline$\cdot \mid 9 V \Delta$ & . Mt & $V / r r \pm r / .$. & $V / \cdot \Lambda \pm r / f 1$ & آمادكى رويارويى & \\
\hline.$\cdot r$ & $r / r$ & $\operatorname{s/\Lambda } \Delta \pm r / / F$ & $\Delta / \wedge \Delta \pm r / r)$ & حمايت از خود & \\
\hline$<\cdot \mid \cdot \cdot 1$ & $|Q / 9|$ & $V V / \cdot \Lambda \pm \mid r / T \Delta$ & $\Delta Q / 9 V \pm \mid F / \Delta V$ & كل ال & \\
\hline$\cdot / \cdot V r$ & $1 / 11$ & $\varphi / \cdot \Delta \pm 1 / \cdot \Delta$ & $\Gamma / M \Lambda \pm \cdot / q \mu$ & ميل ل & عملكرد جنسى \\
\hline$\cdot / \cdot V F$ & $1 / 1$ & $4 / 91 \pm \cdot / 91$ & $r / \cdot V \pm \cdot / Q r$ & تحريك روانى & \\
\hline$<\cdot \mid \cdot \cdot 1$ & 9191 & $\Delta / \Delta \varphi \pm 1 / 1 r$ & $r / \Delta 1 \pm \cdot / 91$ & رطوبت مهبلى & \\
\hline$\cdot / \cdot \wedge V$ & $1 / \mathrm{V} \Lambda$ & $r / 9 \Delta \pm \cdot / 19$ & $r / r \Delta \pm \cdot / v \cdot$ & اركاسم & \\
\hline$<\cdot \mid \cdot \cdot 1$ & $r / \Lambda \Delta$ & $\Delta / T T \pm \cdot / 9 \Delta$ & $r|\Delta| \pm \cdot|\Lambda|$ & رضايتمندى & \\
\hline$\cdot / 1 \cdot r$ & $1 / 90$ & r/rq $\pm \cdot / v q$ & $r / G T \pm \cdot / F \Lambda$ & درد جنسى & \\
\hline$<\cdot \mid \cdot \cdot 1$ & 91.4 & $r \varepsilon / 91 \pm r / q r$ & $r \cdot / r F \pm r / l l$ & كل ل & \\
\hline$\cdot 1 \cdot v 9$ & $1 / v 9$ & $|V / q T \pm F /| \Delta \Delta$ & $\mid q / \Lambda r \pm r / \Lambda r$ & رضايت & رضايت جنسى \\
\hline$\cdot \mid \cdot r l$ & $r / 19$ & $19 / 99 \pm r / \Delta \Lambda$ & $\mid Q / A D \pm r / 4 r$ & ارتباط & \\
\hline$\cdot / \Delta \wedge \Delta$ & $\cdot / \Delta \omega$ & $|\Lambda / q| \pm \Delta /{ }^{4} \Lambda$ & $\mid N / G T \pm 9 / 1 Q$ & سازكارى & \\
\hline$\cdot|r \Delta|$ & $1 / 19$ & $r \cdot / r q \pm r / A v$ & $|9 / \Lambda| \pm \Delta / V F$ & اضطراب رابطه اي & \\
\hline$\cdot / r F \Delta$ & .190 & $r / / F q \pm \Delta / r$. & $r \cdot / \Lambda 9 \pm \Delta / 9 \Lambda$ & اضطراب شخصى & \\
\hline.$/ \cdot r q$ & $r / .9$ & $q \Delta / r \Lambda \pm 1 \Delta / 9 \Delta$ & $9 r / 00 \pm ו r / 1 \%$ & كل & \\
\hline
\end{tabular}

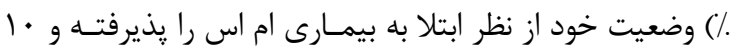

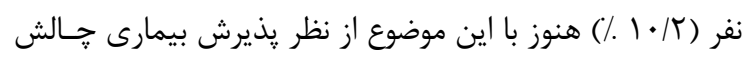

دارند.

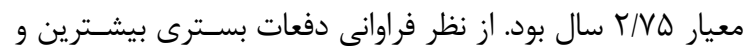

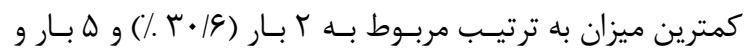

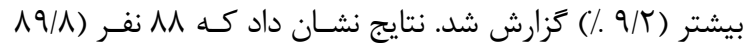


با روند رو به رشدى همراه بوده است. ايسن رونـد، بـهـ ويـزّه در

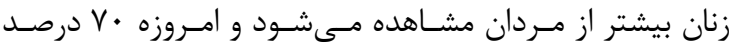

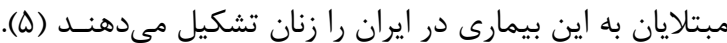

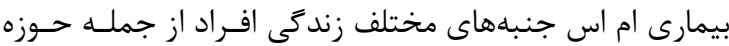
روابط جنسى را درگير مى كند. مكانيسم اثركذارى اين بيمارى

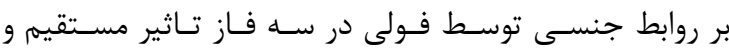
غيرمستقيم بر وضعيت جسمانى و همجنين تـاثير بـر وضـعيت روانشناختى، احساسى، اجتماعى و فرهنگگى تشـريح شـده اسـت

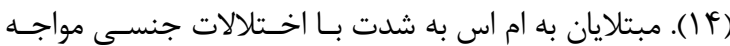
مىشوند كه مىتواند رضايت آنان از روابط جنسـى رانيـز متــاثر

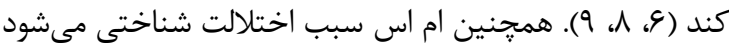

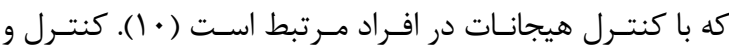

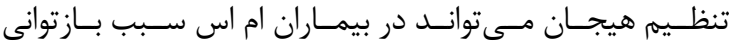
شناختى شده و به بهبود ثبات روانى آنان كمـك كنـد (r ()). بـر

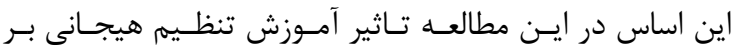

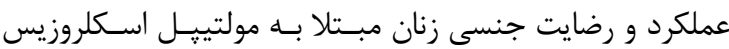

مراجعه كننده به مركز تحقيقات ام اس ايران بررسى شد.

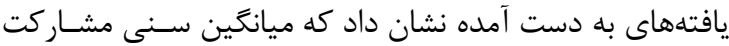

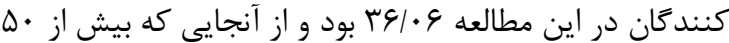
درصد از آنان داراى ه الى · ا ســال سـابقه ابـتلا بـهـ بيمـارى بودند، مىتوان نتيجه گرفت كه اكثر مشاركت كنندگًان در اين مطالعه در بازه زمانى شايع اين بيمارى در زنـان، يعنـى فا ك تـا

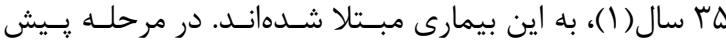
آزمون وضعيت تنظيم هيجانى، Nه/V درصد افراد در سطح كم و متوسط بودند كه بعد از مداخله به له/ V درصد كاهش يافت. ختلال در هيجانات يكى از مشكلات شايع در افراد مبـتلا بـهـ ام اس است. Phillips و همكارانش در مطالعه خـود در بريتانيـا بــه

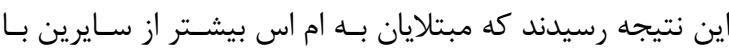
مشكلات تنظيم هيجانى و كنترل هيجانات مواجه هستند و ايسن

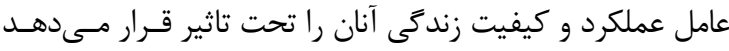

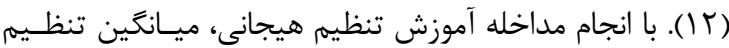

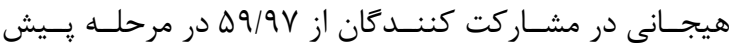

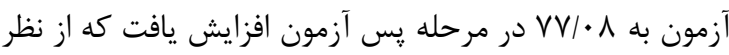

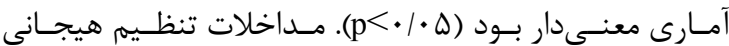

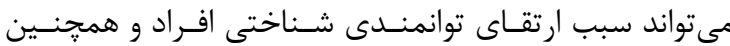

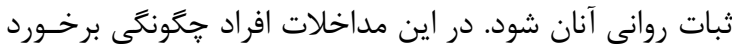

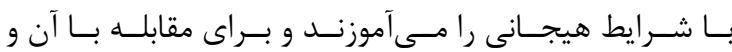

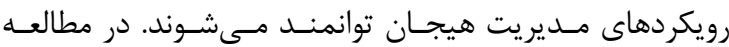
صادقى و همكارانش نيز آموزش تنظيم هيجانى سـبب كـاهش

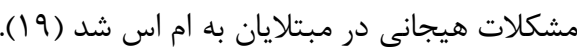

وضعيت تنظيم هيجانى، رضايت و عملكرد جنسى زنان مبتلا بـهـ م اس در دو مقطع زمانى قبل و بعد از مداخله تنظـيم هيجـانى

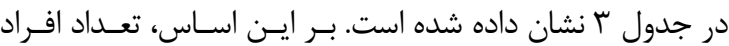
داراى وضـعيت تنظـيمم هيجـان و رضـايت جنسـى كـم بعـد از آموزش به صفر نفر تقليل يافت. در مورد عملكرد جنسى نيز اين

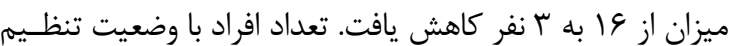

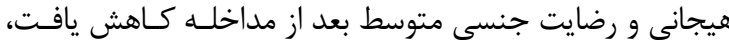
اما اين تعداد در زمينه عملكرد جنسـى فاقـد تغييـر (در هـر دو دو

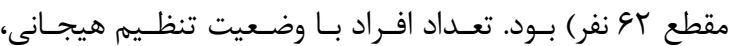
رضايت و عملكرد جنسى زياد بعد از مداخله افزايش يافتـ، ايسن

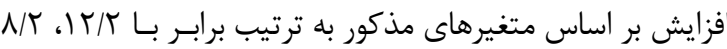

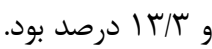
ميـانگين و انحـراف معيـار نمـرات متغيرهــاى تنظـيم هيجـانى، رضايت و عملكرد جنسى و ابعاد آنها در دو مرحله ييش آزمون و و

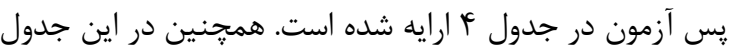
نتايج آزمون تى زوجى براى مقايسه ميانخين متغيرها قبل و بعـد ز مداخله، قابل مشاهده است. ميانخين وضعيت تنظيم هيجـانى

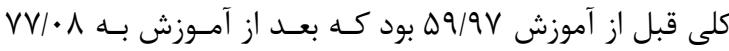
افزايش يافت ( ( • • (p). همجنين نتايج نشان دهنده افـزايش معنى دار ميانخين تمامى ابعاد تنظيم هيجـانى (بــه جــز آمـادگى

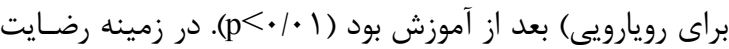

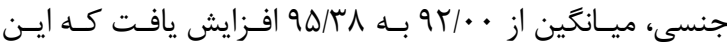

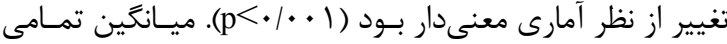

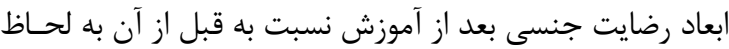
عددى افزايش داشت، اما افزايش ميانگين فقط در بعد ارتبـاط از

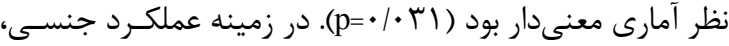
نتايج نشان دهنده افزايش و و واحدى اين متغير بعد از انجـام

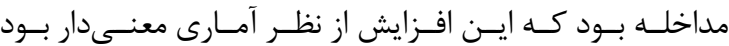

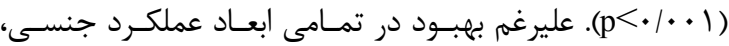

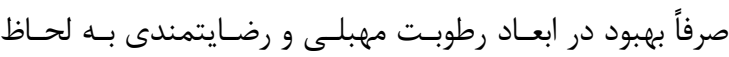

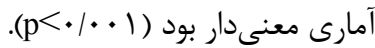

بحث شيوع روزافزون بيمـارى ام اس در جهـان، ايـن بيمـارى را بـــ عنوان يكـى از جــالشهــاى اصـلى سيسـتم هـاى بهداشـتى و

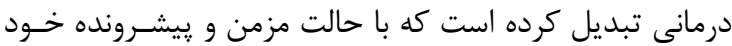
تاثير قابـل ملاحظـهاى در كـاهش كيفيـت زنـد كى و افـزايش نـاتوانى دارد و همجنــين سـبب مــرى زودرس در مبتلايــان مىشود (ז). در ايران نيز شيوع اين بيمارى طى ســ ساليان اخيــ 
همكارانش تقريباً نيمسى از زوجــين نابـارور از رضـايت جنسىى

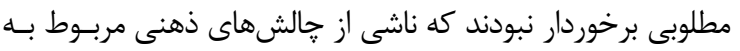

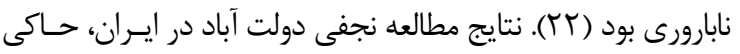

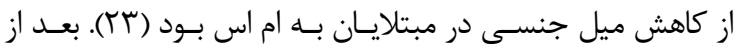

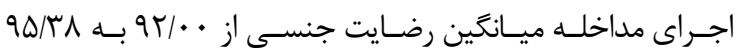

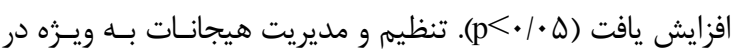
مورد بيماران مبتلا به ام اس كه با جالشهاى متعدد ذهنى مواجه

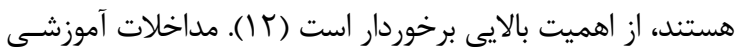

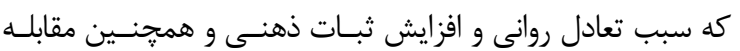
صحيح با منابع هيجان شـود، مسىتوانـد موجـب افـزايش رضـايت جنسى در اين افـراد شـود. در مطالعـه صـورت كرفتــه در كانـادا، مداخله درمان روانشناختى سبب بهبود رضايت جنسـى مبتلايـان

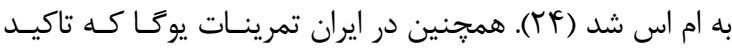

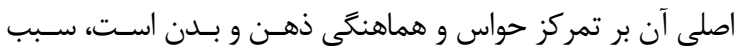
بهبود رضايت جنسى زنان مبتلا به ام اس شد (ب (Y).

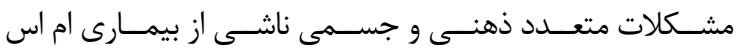

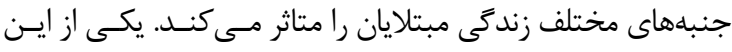

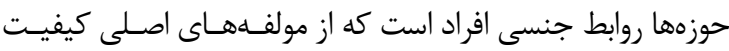
زندكى محسوب مىشود. جالشهاى شناختى و ضعف در مديريت روان و مقابله با شرايط هيجانى يكى از علل اصلى تضعيف عملكـرد

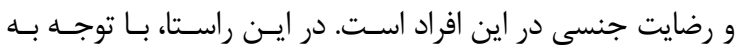
اثربخشى مداخله تنظيم هيجانى، طراحى و اجراى اين مداخله بــه

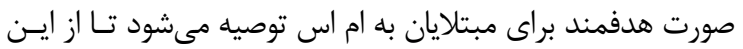

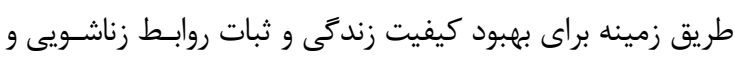
زندگى مشترك آنان فراهم آيد.

\section{تشكر و قدردانى}

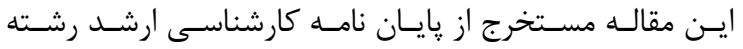

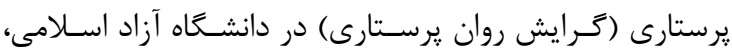

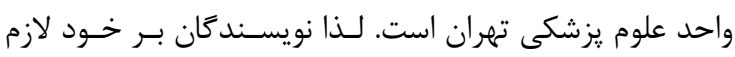

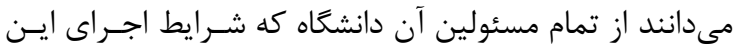
مطالعه را فراهم كردند، تشـكر و قـدردانى كنــــ. همجٍنـين از

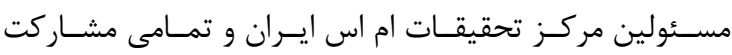
كنندگًان در اين مطالعه، متشكر و سياسگز مراريم.
دومين متغير مورد بررسى در اين مطالعه، عملكرد جنسى بود.

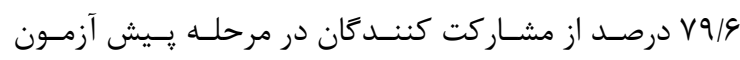

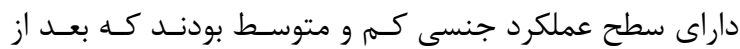

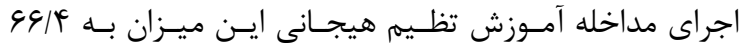
درصد كاهش يافت. عملكرد جنسى افراد به صورت مسـتقيم و غيرمستقيم به دليل تغييرات فيزيولوزيك و جسمى تحت تاثير بيمارى ام اس قرار مى گَيرد. كـاهش تعـادل، ضـعف عضـلانى، كاهش سرعت انتقال ريـامهـاى عصـبى و همجنــين تغيـيـرات روانى نظير كاهش تمركز مىتواند بر عملكرد جنسى افراد تاثير

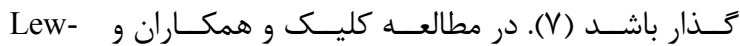

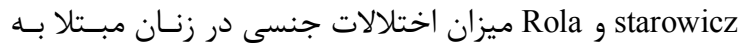

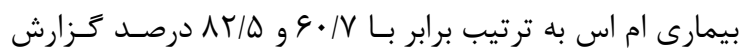

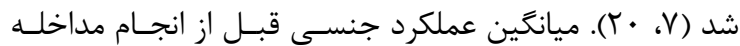

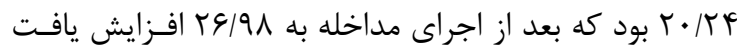

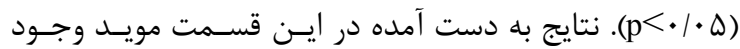

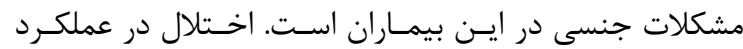
جنسى به صورت كمبود يا كاهش ميل جنسى، كـاهش لـذت،

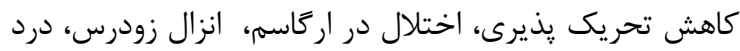
حين مقاربت از مشكلات بيمـاران مبــتلا بـهـ ام اس اسـت (ع).

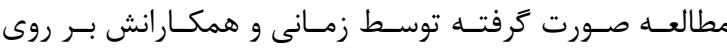

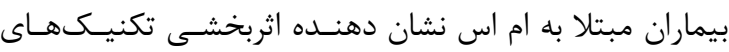
آموزشى در بهبود عملكرد جنسى از ابعاد مختلـف اسـت ( (Y).

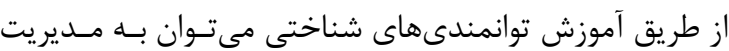

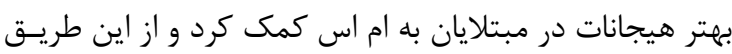
زمينه براى بهبود عملكرد جنسى آنان فراهم مىشود. آخرين متغير مورد بررسى در اين مطالعه، رضايت جنسى زمبن زنان

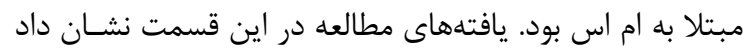

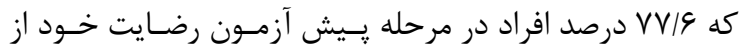
روابط جنسى را در سطح متوسط و كم گزارش كردند كه ايسن

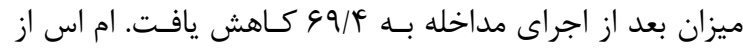
طريق ايجاد مشكلات روانشناختى علاوه بر مشكلات جسمانى، بعدي، سبب كاهش رضايت از روابط جنسى مىشود. همجنين كاهش إنى

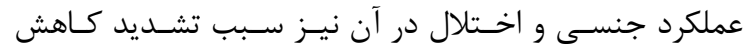

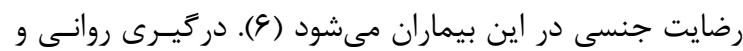

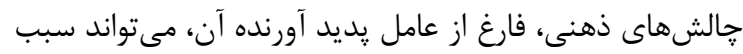

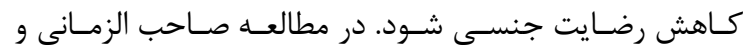

\section{REFERENCES}

1- Brunner LS, Editor. Brunner \& Suddarth's textbook of medical-surgical nursing. London: Lippincott Williams \& Wilkins; 2010.

2-Browne P, Chandraratna D, Angood C, Tremlett H, Baker C, Taylor BV, et al. Atlas of multiple sclerosis 2013: a growing global problem with widespread inequity. Neurology 2014; 83:1022-24. 
3-Mousavizadeh A, Dastoorpoor M, Naimi E, Dohrabpour K. Time-trend analysis and developing a forecasting model for the prevalence of multiple sclerosis in Kohgiluyeh and Boyer-Ahmad Province, southwest of Iran. Pub health 2018; $14: 123-154$.

4-Eskandarieh S, Heydarpour P, Elahami SR, Sahraian MA. Prevalence and Incidence of Multiple Sclerosis in Tehran, Iran. Iran J Public health 2017; 46:699.

5-Elhami S-R, Mohammad K, Sahraian MA, Eftekhar H. A 20-year incidence trend (1989-2008) and point prevalence (March 20, 2009) of multiple sclerosis in Tehran, Iran: a population-based study. Neuroepidemiology 2011; 36:141147.

6-Guo Z-N, He S-Y, Zhang H-L, Wu J, Yang Y. Multiple sclerosis and sexual dysfunction. Asian J Androl 2012; 14:530.

7-Celik DB, Poyraz EÇ, Bingöl A, İdiman E, Özakbaş S, Kaya D. Sexual dysfunction in multiple sclerosis: gender differences. J Neurol Sci 2013; 324:17-20.

8-Merghati-Khoei E, Qaderi K, Amini L, Korte JE. Sexual problems among women with multiple sclerosis. J Neurol Sci 2013; 331:81-85.

9-Cordeau D, Courtois F. Sexual disorders in women with MS: assessment and management. Ann Phys Rehabil Med 2014; 57:337-347.

10- Bicudo-Fürst MC, Leite PHB, Glina FPA, Baccaglini W, de Carvalho Fürst RV, Bezerra CA, et al. Female sexual function following surgical treatment of stress urinary incontinence: systematic review and meta-analysis. Sex Med Rev 2017; 331:81-85.

11- Sahebalzamani M, Hosseinigolafshani SZ, Rashvand F. The effectiveness of a behavioral program on severity of urinary incontinence among iranian women with multiple sclerosis. Int J Epidemiol Res 2017; 4:240-244.

12- Phillips LH, Henry JD, Nouzova E, Cooper C, Radlak B, Summers F. Difficulties with emotion regulation in multiple sclerosis: Links to executive function, mood, and quality of life. J Clin Exp Neuropsychol 2014; 36:831-842.

13- Phillips LH, Saldias A, McCarrey A, Henry JD, Scott C, Summers F, et al. Attentional lapses, emotional regulation and quality of life in multiple sclerosis. Br J Clin Psychol 2009; 48:101-106.

14- Berking M, Znoj H. Development and validation of a self-report measure for the assessment of emotion regulation skills (SEK-27). Psychol Psychother 2008; 56:141-153.

15- Mohammadi R, Bahari Z, SomayeRobat M, Ahmadian SMS, Karimi R. Reliability, validity, and normalization of berking's emotion regulation skills questionnaire in the students of Police University. J Police Med 2015; 4:105-112.

16- Rosen CB J, Heiman S, Leiblum C, Meston R, Shabsigh D, Ferguson R, et al. The Female Sexual Function Index (FSFI): a multidimensional self-report instrument for the assessment of female sexual function. J Sex Marital Ther 2000; 26:191-208.

17- Fakhri A, Pakpour AH, Burri A, Morshedi H, Zeidi IM. The female sexual function index: translation and validation of an Iranian version. J Sex Med 2012; 9:514-523.

18- Meston C, Trapnell P. outcomes assessment: development and validation of a five-factor sexual satisfaction and distress scale for women: the sexual satisfaction scale for women (SSS-W). J Sex Med 2015; 2:66-83.

19- Sadeghi M, Khah ZI, Javadi MH, Lavasani MG. An investigation the effectiveness of emotion regulation training on the reduction of cognitive-emotion regulation problem in patients with multiple sclerosis. Intl J Phys Beh Sci 2015; 2:23-28.

20- Lew-Starowicz M, Rola R. Prevalence of sexual dysfunctions among women with multiple sclerosis. Sex Disabil 2013; 31:141-153.

21- Zamani M, Tavoli A, Khasti BY, Sedighimornani N, Zafar M. Sexual therapy for women with multiple sclerosis and its impact on quality of life. Iran J Psychiatry 2017; 12:58-65.

22- Sahebalzamani M, Farahani H, Mostaedi Z, Sokhanvar M. The relationship between health literacy with sexual function and sexual satisfaction in infertile couples referred to Royan Institute. Int J Fertil Steril 2017; 12:136-141.

23- Najafidoulatabad S, Mohebbi Z. Yoga effects on physical activity and sexual satisfaction among Iranian women with multiple sclerosis: a randomized controlled trial. Afr J Tradit Complement Altern Med 2014; 11:78-82.

24- Blackmore DE, Hart SL, Albiani JJ, Mohr DC. Improvements in partner support predict sexual satisfaction among individuals with multiple sclerosis. Rehabil Psychol 2011; 56:117-122. 